\title{
El aula como Espacio Arquitectónico en la docencia 2.0 (II)
}

\author{
Alonso Pereira, José Ramón; Abelleira Doldán, Miguel; Blanco Lorenzo, Enrique; \\ Caridad Graña, Juan Antonio; Río Vázquez, Antonio S.
}

Grupo de Innovación Educativa en Historia de la Arquitectura,

E. T. S. de Arquitectura, Universidade da Coruña.

\section{RESUMEN}

Desde el año 2007 el Grupo de Innovación Educativa en Historia de la Arquitectura (Grupo IALA), a través de la docencia impartida en Introducción a la Arquitectura, ha desarrollado su actividad en la aplicación a la docencia de las TICs, a través de la creación de un entorno virtual docente (ENVIDO), articulado alrededor del blog de la asignatura (http://iala.udc.es/) y a la utilización de herramientas abiertas Web 2.0.

La preocupación por la docencia interactiva y la aplicación de las nuevas tecnologías a la docencia ha llevado al grupo a la reflexión sobre el espacio del aula como espacio arquitectónico orientado a esta nueva docencia.

La presente comunicación pretende exponer los avances realizados en la práctica explorando y proponiendo alternativas a la concepción tradicional del aula en la docencia. Estas alternativas resuelven problemas programáticos y necesidades generados por la nueva relación profesor-guía / alumno, en la que éste último se coloca como Centro, intelectual y espacial, del aprendizaje. Definen, además, las herramientas tecnológicas precisas y su integración coherente en el espacio arquitectónico del aula más allá de su mera utilización, desde el convencimiento de que la Arquitectura del aula contribuye a la formación y a la educación integral del titulado universitario.

PALABRAS CLAVE: Arquitectura, aprendizaje, aula, metodología, proyecto 


\section{CITA RECOMENDADA:}

Alonso Pereira, J.R.; Abelleira Doldán, M.; Blanco Lorenzo, E.; Caridad Graña, J.A.; Río Vázquez, A.S. (2019): El aula como Espacio Arquitectónico en la docencia 2.0 (II). En De la Torre Fernández, E. (ed.) (2019). Contextos universitarios transformadores: construíndo espazos de aprendizaxe. III Xornadas de Innovación Docente. Cufie. Universidade da Coruña. A Coruña (pág.3-14).

DOI capítulo: https://doi.org/10.17979/spudc. 9788497497121.003

DOl libro: https://doi.org/10.17979/spudc.9788497497121

\section{ABSTRACT}

Since 2007, the IALA Group, through the teaching given in Introduction to Architecture, has developed its activity in the application to the teaching of ICTs, through the creation of a virtual teaching environment (ENVIDO), articulated around of the subject's blog (http://iala.udc.es/), and the use of open Web 2.0 tools.

The concern for interactive teaching and the application of new technologies to teaching has led the group to reflect on the space of the classroom as an architectural space oriented to this new teaching. The present communication aims to expose the advances made in practice by exploring and proposing alternatives to the traditional conception of the classroom in teaching. These alternatives solve programmatic problems and needs generated by the new teacher-guide / student relationship, in which the latter is placed as Center, intellectual and spatial, of learning. They also define the precise technological tools and their coherent integration in the architectural space of the classroom beyond its mere use, based on the conviction that the classroom architecture contributes to the education and integral education of the university graduate.

KEY WORDS: Architecture, learning, classroom, methodology, project 


\section{INTRODUCCIÓN}

La primera materia en la cual el alumno de la Escuela Técnica Superior de Arquitectura de A Coruña, entra en contacto con el triple hecho reflexivo, proyectual y constructivo que definen la disciplina, es la asignatura de Introducción a la Arquitectura, actualmente encuadrada en el primer cuatrimestre del Grado en Estudios de Arquitectura. Desde el año 2007 el Grupo de Investigación en Historia de la Arquitectura IALA, de la Universidade da Coruña ha ido experimentando y desarrollando un conjunto de metodologías activas de innovación docente a través de la asignatura.

Una parte de estas actividades, ha tenido su objetivo en la aplicación de las Tecnologías de la Información y la Comunicación en la docencia presencial y no presencial, generando un Entorno Virtual Docente (ENVIDO), articulado alrededor del blog de la asignatura (http://iala.udc.es/). Otra se ha centrado en el desarrollo de metodologías activas para el estudio, análisis y comprensión del espacio arquitectónico empleando el aula como herramienta de aprendizaje. El Proyecto del aula como un todo integrado orientado a la docencia innovadora constituye el punto de conexión entre ambas líneas de trabajo e investigación

La preocupación por la docencia interactiva y la aplicación de las nuevas tecnologías a la docencia ha llevado al grupo IALA a la reflexión sobre el espacio del aula como espacio arquitectónico orientado a esta nueva docencia, en el que se coloca como centro del aprendizaje al alumno, según lo señalado en diferentes trabajos anteriores desarrollados por el grupo. La introducción del ordenador portátil, la tableta 0 el teléfono inteligente, nos obliga a la reconsideración del aula en su concepción tradicional como espacio de aprendizaje, cerrado e inmóvil en su concepción. La distribución habitual de un orador activo enfrentado a un alumno-receptor pasivo está marcada por la obsolescencia del planteamiento y la ineficacia de sus resultados. En el nuevo modelo aplicado por IALA, el profesor que actúa como guía debe tener la capacidad de orientar al alumno, interactuando con los contenidos que el propio alumno individualmente o como grupo, busca, encuentra y propone. El profesor y los alumnos 
deberán tener la capacidad de manipulación del espacio arquitectónico y sus elementos configuradores para adaptarlos a cada necesidad docente marcada por el cambio y la adaptación. La capacidad de movimiento del profesor y el alumno en el aula, y la reconfiguración de ésta en función del material de trabajo propuesto y utilizado en cada clase se convierten en temas capitales. El aula deberá ser también un punto de conexión con el exterior, de modo que permita la accesibilidad a los recursos arquitectónicos globales desde su posición espacial local.

En el modelo aplicado, el alumno y sus recursos de aprendizaje son puestos en el Centro de atención pedagógica y en el Centro del espacio arquitectónico, considerando al resto de los recursos de aprendizaje y al propio docente, como periféricos desde el punto de vista físico. En la experiencia llevada a cabo durante estos años en la Escuela de Arquitectura, se le propone, además, al alumnado de modo específico, la utilización del espacio del aula como espacio de su primera experiencia arquitectónica, como lugar del proyecto que ha de reconfigurar progresivamente a lo largo de la duración del curso, hasta ajustarlo a las necesidades de aprendizaje de las que va tomando conciencia, al tiempo que relaciona las ideas espaciales con los problemas funcionales y constructivos, algo que resulta de especial interés desde nuestra visión dual como profesores y arquitectos.

Durante el curso 2017-2018 el grupo ha llevado adelante nuevas iniciativas docentes en el marco descrito que han puesto en juego nuevas experiencias en la utilización del espacio arquitectónico, en la docencia de universitaria y específicamente en la docencia de la Arquitectura. En el presente documento se expondrán las iniciativas descritas en su condición de avance en la línea de trabajo desarrollada.

\section{DESCRIPCIÓN DE LAS NUEVAS EXPERIENCIAS}

Para lograr la meta docente de introducir al alumno en la disciplina arquitectónica entendida como oficio, tenemos a nuestra disposición diferentes herramientas, pero quizás la más potente por ser física y el hábitat cotidiano del profesor-arquitecto y del alumno-futuro 
arquitecto, es aquella que normalmente ignoramos: el aula. Podemos ver el aula como un hecho dado o plantearnos que se trata de un problema de proyecto. ¿Qué implica entender el aula como un auténtico escenario de aprendizaje susceptible de ser pensado y proyectado? No podemos obviar las palabras de Winston Churchill "We shape our buildings; thereafter they shape us".

El aula se convierte entonces en una útil herramienta para la docencia de la Arquitectura, un entorno integrador orientado a la consecución de los objetivos previstos en la asignatura, un lugar de pensamiento, debate, análisis y objeto de Proyecto.

El aula debe ser analizada en esta concepción en una triple vertiente:

1.- El aula como espacio arquitectónico objeto de aprendizaje y proyecto en función de un nuevo programa y existenzemínimum en la docencia universitaria, en relación a los trabajos que sobre ella y en ella realizan los alumnos. Otras posibilidades de enseñanza se plantean en el resto de los espacios de la Escuela de Arquitectura, entendidos como Elementos Singulares para constituir un nuevo Nivel de Agregación, el edificio docente.

2.- El aula como ventana de comunicación con el mundo, a través de las oportunidades planteadas por las nuevas tecnologías y el profesor nómada.

3.- El aula como objeto de proyecto arquitectónico, planteado directamente al alumno.

\subsection{EL AULA COMO ESPACIO ARQUITECTONICO OBJETO DE APRENDIZAJE Y PROYECTO} (EXISTENZEMINIMUN): EL CASO DEL ALUMNO QUE APRENDE HACIENDO.

La reflexión sobre los cambios que la introducción de las nuevas tecnologías en la docencia interactiva, propuesta por el llamado Plan Bolonia, propician en el espacio arquitectónico del aula ha sido objeto de trabajo por parte de los miembros del Grupo de Innovación Educativa en Historia de la Arquitectura, desde el inicio.

El uso del ordenador portátil, la tableta y/o el teléfono inteligente, como herramientas físicas para la docencia, el acceso a Internet y las posibilidades de uso de las redes sociales como ventanas de acceso al exterior, obligan a la reconsideración de la realidad física del aula como 
espacio arquitectónico especializado y proyectado para el aprendizaje. Si el uso, si el programa en términos arquitectónicos, cambia, es necesario el replanteamiento de la arquitectura que le da respuesta, en tanto que herramienta de innovación. El nuevo espacio arquitectónico para el aprendizaje superior continúa teniendo su célula básica, su existenzminimun, en el aula, pero esta tiene que ser redefinida en función de su nuevo uso. Sus usuarios deben disponer de un espacio flexible, reconfigurable y adaptable a cada instante temporal individual de uso diferente. Todas las capas, entendidas como articuladoras de redes conectadas, que configuran el espacio arquitectónico (su Firmitas, su Utilitas y su Venustas) deben de supeditarse a este planteamiento.

A los instrumentos tradicionales de este espacio mínimo, pizarras, proyectores y mobiliario dispuesto en matriz orientada, pensados para la docencia expositiva tradicional y que constituyen una red de equipamiento, en la que un profesor-orador activo se enfrenta a un alumno-receptor pasivo, se opone un nuevo tipo de docencia interactiva que plantea diferentes modos de ocupación del espacio en función de los distintas clases de aprendizaje planteadas en relación con el objeto a conocer y del propio alumno como sujeto central de conocimiento. lluminación natural y artificial, conectividad, sonido, climatización, son redes que deberán también adaptarse a este nuevo paradigma. La capa mobiliario, arquitectura de pequeña escala, debe aprovechar las oportunidades que el Internet de las Cosas plantea sin olvidar que cada una de las piezas constituyen objetos de aprendizaje arquitectónico.

La metodología de trabajo del proyecto arquitectónico, estructurada en los principios secuenciales e iterativos de análisis, ideación, composición, ejecución y uso, se ha planteado útil para proponer al alumnado un trabajo en el que es protagonista de la reconfiguración espacial del aula y sus redes, en función de las necesidades que el propio alumno detecta para su aprendizaje. Todos los objetos del aula son susceptibles de uso y transformación: las mesas se pueden convertir en escenario, las paredes en soportes de exposición, siempre con la Forma como objetivo y el axioma tomista de que "la Belleza es la Verdad", de fondo. 
Los propios alumnos actuaron como protagonistas del trabajo diseñando y ejecutando a lo largo del cuatrimestre, la reconfiguración del aula, modificando las redes existentes (aquellas sobre las que es posible actuar) en función de las necesidades, elaborando planos y propuestas hasta alcanzar mejores resultados.

El profesor, forma parte del equipo asumiendo su papel de dirección, y actúa como guía crítico sobre los resultados de su primer proyecto arquitectónico, introduciendo variables nuevas que obligan a reconsiderar la solución en un proceso de mejora constante y descubre también la ineficiencia de algunas de las soluciones planteadas para el espacio arquitectónico. Se propuso el entendimiento del aula como suma de redes de conocimiento y físicas, conectadas, que configuran de modo contemporáneo el espacio.

\subsection{EL AULA COMO VENTANA DE COMUNICACIÓN Y NODO DE ACCESO A LAS NUEVAS TECNOLOGÍAS DE LA COMUNICACIÓN. LA EXPERIENCIA DE LA PROFESORA NÓMADA.}

Como parte de los contenidos impartidos en la asignatura de Introducción a la Arquitectura, se propone a los alumnos, según lo recogido en la guía docente, el análisis de la vida y la obra de tres Maestros de la arquitectura del Movimiento Moderno en el siglo XX. Uno de estos Maestros abordados es el arquitecto alemán Mies van der Rohe, director en su momento de la escuela de Arquitectura de la Bauhaus en Alemania, y con posterioridad del Departamento de Arquitectura en el Instituto Tecnológico de Illinois (ITI). Se plantea al alumnado el análisis y entendimiento de las características de sus obras emblemáticas, considerando el conocimiento de las herramientas proyectuales utilizadas por el arquitecto, como paso previo al proyecto de los que ellos serán protagonistas.

Los edificios analizados se muestran al alumno mediante presentaciones tradicionales elaboradas por el profesorado y la transmisión de fuentes bibliográficas, además en la utilización de nuevas metodologías y nuevas herramientas docentes, se propone al alumnado a través de la utilización de las redes TICs, que aporten planimetrías, análisis o visitas a las 
distintas obras. Se incide especialmente en la verificación de la fiabilidad de las fuentes de las que los alumnos obtienen los datos.

Uno de los edificios emblemáticos objeto del trabajo es el que albergaba el departamento de Arquitectura del ITI, el Crown Hall de Chicago, proyectado por Mies entre 1950 y 1956 como parte del Máster Plan del Campus del Instituto. Una de las profesoras de Introducción a la Arquitectura, Zaida García Requejo, se encontraba en el curso 2017-2018 realizando su tesis doctoral sobre el arquitecto alemán bajo la dirección del profesor Mahjoub Elnimeiri, del ITI. Se hizo coincidir la clase que sobre el maestro se impartió en la asignatura de Introducción, con una visita de trabajo de la profesora a Chicago. De este modo se pudo llevar adelante la explicación arquitectónica del edificio mediante videoconferencia, en la que se planteó un recorrido guiado al Crown Hall, realizado en directo. Se utilizó para la actividad la aplicación YouTube y llamada telefónica vía Whatsapp, de modo que los alumnos pudieron formular preguntas sobre la exposición planteada

La actividad tuvo una alta aceptación verificándose la implicación del alumnado en el trabajo y, mediante el desarrollo de actividades posteriores sobre la Arquitectura de su autor, una mejor comprensión del carácter espacial, lingüístico y constructivo de la misma al hacerla suya el alumnado, de modo más intenso. Desde el punto de vista técnico, la versatilidad e inmediatez de la tecnología 2.0 facilitó en gran medida, mediante la utilización del teléfono inteligente, la realización de esta actividad, que se ha repetido en el presente curso 2018/2019 con otros arquitectos y otras arquitecturas y que se incorporará en el futuro como actividad integrada en las asignaturas en las que el grupo IALA tiene docencia.

\subsection{EL AULA COMO OBJETO DE PROYECTO ARQUITECTÓNICO: EL EXTRAÑO CASO DEL CONCURSO DEL PROFESOR ARQUITECTO}

Uno de los modos fundamentales de aprendizaje de la Arquitectura es la propia vivencia personal. Tras una primera experiencia en la segunda sesión del cuatrimestre en la que se les planteó a los alumnos una reconfiguración del aula por medio del cambio de posición de las 
mesas y las sillas, y tras la exposición teórica del tema "Arquitectura y Proyecto", se propuso, al finalizar el tercer mes del curso, un concurso de proyectos para la reorganización del aula habitual de docencia interactiva. Conviene precisar que dicha aula ocupa una posición en esquina, tiene una planta en $L$ con dos lados acristalados y dos entradas. Como elementos fijos hay un proyector y una pantalla. A partir de estos datos y después del primer intento referido que les sirvió para interiorizar que en Arquitectura es clave saber qué se va a hacer antes de hacerlo, a los estudiantes se les pidió que realizasen dos propuestas para 14 alumnos y 2 profesores, una con proyección de imágenes y la otra sin ningún condicionante fijo.

En primer lugar, enviaron los lemas con los que iban a concursar y se les dio una semana como plazo para la preparación de las propuestas. El día que las entregaron tuvieron que adoptar un segundo rol, puesto que de concursantes pasaron a ser jurados. Todas las propuestas, hechas con los mismos criterios de representación, se colgaron conjuntamente. Cada estudiante tenía que votar a las dos que considerase mejores. De este modo se hizo una selección que permitió una segunda fase de jurado con las tres opciones más votadas. Una vez repetido el proceso, aunque en esta fase sólo se podía votar a una de las tres, el jurado eligió a la propuesta ganadora.

Tras esto, se produjo un nuevo cambio de roles, puesto que el estudiante autor del proyecto vencedor se convirtió en director de obra y supervisó el trabajo de sus compañeros, encargados de la materialización de la propuesta ganadora, dando las instrucciones que consideró oportunas. Una vez que, a juicio del director de obra, ésta había finalizado, se la entregaba al cliente - profesor, quien verificaba la validez de la solución, realizando los comentarios pertinentes. Esto se hizo para las dos propuestas del concurso. Lógicamente, al variar las condiciones de partida, proyección en pantalla 0 no, las respuestas fueron muy distintas. En la primera, al haber un punto focal fijo, la solución estaba condicionada y la zona que se ocupó fue la más próxima a la pantalla. En la segunda, con una geometría claramente diferente, la zona ocupada fue la de la intersección entre los dos brazos de la L, aprovechando 
la mayor dimensión de la diagonal. En los tres subgrupos en los que se realizó la experiencia, las soluciones vencedoras fueron similares.

El resultado fue que el alumnado llegó a ser plenamente consciente de la importancia de la configuración espacial del aula para permitir un tipo u otro de docencia y que aquélla debe ser capaz de adaptarse a los requerimientos y peculiaridades de las diversas metodologías que se puedan emplear. Asimismo, aspectos determinantes como la forma y la dimensión, que son elementos claves en el proceso de significación arquitectónica, fueron asimilados por los alumnos de un modo natural, mucho más profundo que una simple explicación teórica verificable en una prueba objetiva. Aprender haciendo es fundamental en la formación de un arquitecto. $Y$ el aula entendida como herramienta docente 0 , lo que es lo mismo, como elemento activo en el proceso de aprendizaje, puede facilitar la labor tanto del profesorado como del alumnado.

\section{RESULTADOS}

El aula es un objeto válido para la enseñanza innovadora de la Arquitectura, pero debe ser reformulada, basando la actuación en su entendimiento espacial constituido ontológicamente como soporte de redes flexibles, mutables y fácilmente manipulables por el equipo profesoralumnado, en el que la conectividad de los objetos deberá ser fundamental y para cual la forma arquitectónica es un objetivo central. El proceso de formación del alumno de Introducción a la Arquitectura que aprende haciendo en su aula, es claramente más eficiente y acelerado que el producido desde la formación tradicional.

La utilización de la estrategia web 2.0 aplicada al carácter nómada del profesor universitario contemporáneo supone una oportunidad para la formación del alumno, acercando de modo sencillo por la usabilidad de las aplicaciones y soportes, a ejemplos emblemáticos de Arquitectura a los futuros arquitectos. Este modo docente podrá extenderse en el futuro, a la posibilidad de que sea el alumno quien asuma el protagonismo, siendo él quien acerca 
determinadas obras que visita a sus compañeros y al profesorado, en un proceso de docencia compartida y autoaprendizaje.

La utilización de la experiencia propia a través de la simulación de situaciones profesionales reales, para la formación del alumno de Arquitectura, constituye una oportunidad y una necesidad que mejora de modo notable los resultados docentes obtenidos. La experiencia del concurso de proyectos para la mejora del aula constituye en protagonista al alumno, propone reflexión sobre el nuevo espacio docente interactivo e incrementa la implicación del alumno notablemente en su formación.

\section{CONCLUSIÓN}

De la línea de trabajo emprendida por el Grupo IALA desde el año 2007 y mantenida en el tiempo, se deduce que el cambio de los modos docentes y la integración de las nuevas tecnologías en el aula, en definitiva el cambio de programa arquitectónico, debe ser respondido a través de un nuevo paradigma proyectual, que aproveche las oportunidades surgidas y defina nuevos espacios arquitectónicos adecuados para el nuevo uso, incrementando la calidad de la formación propuesta y posibilitando su orientación a la excelencia. El cambio y la innovación en la docencia, específicamente en la docencia arquitectónica, no debe entenderse como una situación temporal vinculada la crisis del sistema; ha de convertirse en una estrategia permanente asentada en el tiempo.

\section{REFERENCIAS}

Norberg-Schulz, Christian (1990). Louis I. Kahn, idea e imagen. Madrid: Xarait Castells, Manuel; Borja, Jordi (2004). Local y global. La gestión de las ciudades en la era de la información. Madrid: Taurus

Hertzberger, Herman (2008). Space and Learning. Rotterdam: 010 Publishers. 
